University of Nebraska - Lincoln

DigitalCommons@University of Nebraska - Lincoln

Nutrition and Health Sciences -- Faculty

Publications

Nutrition and Health Sciences, Department of

$12-2011$

\title{
Constructive Developmental Theory: An Alternative Approach to Leadership
}

Anne Marie B. Hunter

Missouri State University - Springfield, AMHunter@missouristate.edu

Nancy M. Lewis

University of Nebraska--Lincoln, nlewis2@unl.edu

Paula K. Ritter-Gooder

University of Nebraska-Lincoln, pgooder@windstream.net

Follow this and additional works at: https://digitalcommons.unl.edu/nutritionfacpub

Part of the Dietetics and Clinical Nutrition Commons

Hunter, Anne Marie B.; Lewis, Nancy M.; and Ritter-Gooder, Paula K., "Constructive Developmental Theory: An Alternative Approach to Leadership" (2011). Nutrition and Health Sciences -- Faculty Publications. 17. https://digitalcommons.unl.edu/nutritionfacpub/17

This Article is brought to you for free and open access by the Nutrition and Health Sciences, Department of at DigitalCommons@University of Nebraska - Lincoln. It has been accepted for inclusion in Nutrition and Health Sciences -- Faculty Publications by an authorized administrator of DigitalCommons@University of Nebraska - Lincoln. 


\title{
Constructive Developmental Theory: An Alternative Approach to Leadership
}

\author{
Anne Marie B. Hunter PhD, RD, LD, FADA, assistant professor, Department of Biomedical Sciences/Dietetics Program, \\ Missouri State University, Springfield \\ Nancy M. Lewis PhD, RD, FADA, professor, Department of Nutrition and Health Sciences, University of Nebraska-Lincoln \\ Paula K. Ritter-Gooder PhD, RD, CSG, LMNT, research assistant, Department of Nutrition and Health Sciences, \\ University of Nebraska-Lincoln.
}

\begin{abstract}
s early as 1954, the critical value of leadership in dietetics was described by Rourke, who wrote, "When the day comes that your executive abilities equal your scientific knowledge, your profession (dietetics) will be secure. Until that day, you will be faced with a constant and unwelcome challenge" (1). Career and leadership skills development have been identified as an area for further attention by American Dietetic Association (ADA) practitioners and student members (2). Creation of the ADA Leadership Institute in 2003 represented an awareness of the need to invest in developing dietetic leaders (3). Proficient leaders are critical in keeping our profession on the cutting edge by identifying areas of need for change and providing leadership for change. Proficient leaders can also serve as role models for members.

Leadership has been identified as essential for success in the 21st century and according to Bennis, "our quality of life amidst the volatility, turbulence and ambiguity of our present day societal context, depends on the quality of our leaders" (4). Leadership research theory has been based on objective measures such as traits, attitudes and performance, intellect, personality, relationships, competencies, and values. Dietetic leadership studies are limited and describe these objective characteristics and leadership styles (5-9). In their review of traditional leadership theory, Gregoire and Arendt (10) suggested that more information is needed about how dietitians develop as leaders. The present article describes one theory of leadership development-constructive developmental theory. Registered dietitians at advanced leadership
\end{abstract}

stages can be identified and factors enabling their development can be studied. This theory provides a subjective approach for studying dietetic leadership and gives insight for leadership development programs.

\section{Constructive Developmental Theory}

Constructive developmental theory differs from traditional leadership theories in that it focuses on the mindset of an individual and not specific traits or characteristics. The mindset of the individual has an impact on his or her leadership ability. Constructive developmental theory has at its origins Jean Piaget's theory of cognitive development, which centers on the process of how human beings "come to know," and the stages of mental growth we travel through acquiring this ability of "abstract symbolic reasoning" (11). Piaget was also cognizant of the fundamental role of language in the construction of meaning and mastery of life. Prominent developmental frameworks include Loevinger's ego development, Kegan's subject-object, Beck and Cowan's spiral dynamics, and Torbert and Cook-Greuter's action logics (12-17).

Developmental theorists assert that human beings actively make sense of experience; that we are meaning makers of our experience, creating maps of reality that change with development. Constructive developmental theorists posit that "persons move through qualitatively different ways of knowing who they are, how the world works, and how they know what they know" and that "leaders as individuals develop over the life course and do so in predictable ways" (18). Most growth in adults is objective or horizontal-that is, learning new skills, new methods, new facts, or pursuing advanced degrees. Subjective development or vertical growth is transformational growth manifested by changes in our form rather than content of understanding, and focuses on how people tend to reason and behave in response to their experience. This vertical development involves transformations of consciousness, seeing the world through new eyes, and changes in interpretations of experience and view of reality. It addresses questions such as: How do people interact? How does a person feel about things? How does a person think? (19).

\section{Leadership Development Spiral}

Vertical human development is illustrated as an ever-widening evolutionary spiral of the stages of lived human experience and how one makes sense of those experiences. There is a logical sequence of growth through the developmental stages, and one lives through the earliest stages before progressing to later stages. Once one has journeyed through an earlier stage, it becomes part of that person. Most human beings do not grow through the entire spiral, but rather settle in the stage that is most familiar or most supported by the environment (17) and (19). Vertical development moves from simple to complex with a demonstrated increase in autonomy, flexibility, tolerance for differences and ambiguity, and a simultaneous decrease in defenses (17). A person may grow horizontally in knowledge acquisition, whereas their vertical development remains the same. 


\begin{tabular}{|c|c|c|c|}
\hline & Stage & Action Logic & Characteristics \\
\hline 可 & $2 / 3$ & Opportunist & $\begin{array}{l}\text { Manipulative; focused on self; external blame; "I win, you lose mentality"; see } \\
\text { feedback as an attack; fragile self-control; hostile humor; sees punishment as } \\
\text { "an eye for an eye." }\end{array}$ \\
\hline \multirow{3}{*}{ 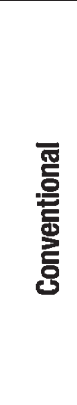 } & 3 & Diplomat & $\begin{array}{l}\text { Avoids overt conflict; wants to be a member of the group; seeks approval; } \\
\text { conforms to social and group norms and standards; righteousness is } \\
\text { prevalent; no self-reflection or recognition of own shortcomings; feedback } \\
\text { heard as personal disapproval. }\end{array}$ \\
\hline & $3 / 4$ & Expert & $\begin{array}{l}\text { Rules by logic and expertise; strong belief systems; usually cognitively grasps } \\
\text { one or more disciplines; perfectionism; serial problem solving; can get stuck } \\
\text { in detail; difficulty prioritizing competing demands; sees feedback as criticism. }\end{array}$ \\
\hline & 4 & Achiever & $\begin{array}{l}\text { Results and goal oriented; future oriented; seeks consensus; self as agent; } \\
\text { initiator; may be unorthodox; self critical; mutuality and equality in } \\
\text { relationships; begins to see complexity; accepts behavioral criticism. }\end{array}$ \\
\hline \multirow{3}{*}{ 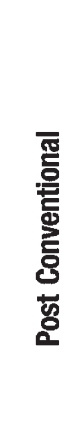 } & $4 / 5$ & Individualist & $\begin{array}{l}\text { Increased comprehension of complexity; turns inward, sees self in } \\
\text { relationship; able to adjust behavior to context; systematic problem solving; } \\
\text { can create decision paralysis; begin to seek out and value feedback. }\end{array}$ \\
\hline & 5 & Strategist & $\begin{array}{l}\text { Creates personal and organizational transformations; recognizes complexity } \\
\text { and interrelationships; problem finding not just problem solving; aware of } \\
\text { paradox and contradiction in system and self; nonhostile humor; deep } \\
\text { appreciation of others; seeks feedback as vital for growth. }\end{array}$ \\
\hline & $5 / 6$ & Alchemist/Magician & $\begin{array}{l}\text { Generates social transformations; highly aware of complexity of meaning } \\
\text { making, dynamic processes; reframe meaning of situations; seeks spiritual } \\
\text { and personal transformations; works with chaos and order; interplay of } \\
\text { awareness, thought, action; aware of continuous self redefinition. }\end{array}$ \\
\hline
\end{tabular}

Figure 1. Stage, Action Logic, and characteristics of leaders using constructive developmental theory. Adapted from references (16), (20-22).

\section{Action Logic States/Stages}

Most developmental psychologists agree that what differentiates leaders is not so much their philosophy of leadership, their personality, or their style of management. Rather it is their internal "Action Logic" or stage of vertical development that impacts how they interpret their surroundings and react when their power or safety is challenged (20). Action Logics are those steps or stages of an individual's journey of mental growth and vertical development in adulthood; or how one makes meaning of themselves and the world $(16,17)$. A person's Action Logic is considered to be their center of gravity; the place where a person is most likely to reason and spontaneously respond and interpret their experiences (16).

Figure 1 describes the stages and characteristics of leadership using the Action Logic model (16), (20-22). Stages are assigned a number from 2 to 5/6 and a corresponding set of characteristics. These stages illustrate the movement from early to later (not lower to higher) stages of develop- ment where Pre-Conventional is seen as the earliest tier of development and Post-Conventional as the later tier of development. Using the example of promoting nutrition care services in health care policy, a registered dietitian at Stage 3 (Diplomat) might avoid contact or discussion with regulatory agencies and perceive feedback as a personal attack. A dietetic leader at Stage 3/4 (Expert) may seek perfectionism in obtaining specific regulatory language for all areas of concern and overlook the need to prioritize advocacy. Any feedback on his/her effort is viewed as criticism. Dietetic leaders at Stage 4 (Achiever) may initiate other efforts to advocate for future needs and begin to understand the complexity or bigger picture of overall health care-related issues. At this stage the leader accepts criticism.

Authentic leadership most closely resembles the Post-Conventional Stages 4/5 (Individualist), 5 (Strategist), and 5/6 (Alchemist/Magician) of development. Dietetic leaders at these later stages of development are very self aware and have an organizational impact. To promote nutrition care services, leaders at these stages may engage within regulatory agencies or institutions that propose health care policy/regulations. These leaders seek out and value feedback from a wide array of stakeholders and are proactive in finding problems that may prevent goal achievement. For example, they allow themselves to be visibly vulnerable in times of crises, thereby creating a trusting environment where others feel comfortable to express their own concerns. Assigning responsibilities to others based on their skill level, in turn, can challenge and mentor others to further personal development.

Previous studies of leaders across industries and organizational levels have identified that $5 \%$ of leaders are at the Pre-Conventional Opportunistic stage; $80 \%$ are within the Conventional tier at the Diplomat, Expert, and Achiever stages; and the remaining $15 \%$ are within the Post-Conventional tier at the Individualist, Strategist, and Alchemist/Magician stages (20, 21). 


\begin{tabular}{|c|c|c|}
\hline $\begin{array}{l}\text { Incomplete } \\
\text { sentence }\end{array}$ & Sample participant Response & $\begin{array}{l}\text { Stage of } \\
\text { leadership } \\
\text { development }\end{array}$ \\
\hline \multirow[t]{4}{*}{ I am... } & I am healthy. & 3 \\
\hline & I am a hard worker. & $3 / 4$ \\
\hline & I am very adaptable having an affinity for knowledge and new surroundings. & 4 \\
\hline & $\begin{array}{l}\text { I am challenged by my recent promotion at work, delighted that my sons are healthy and successful, and } \\
\text { that I am married to a man whom I love and respect; thrilled to have weathered personal and professional } \\
\text { change within the last year, and committed to personal growth and achievement in the next one. }\end{array}$ & $4 / 5$ \\
\hline \multirow[t]{4}{*}{ A good boss... } & A good boss gets me the resources I need. & $3 / 4$ \\
\hline & A good boss encourages creativity and professional involvement. & 4 \\
\hline & A good boss mentors, listens, provides prompt feedback, and usually stays out of the way. & $4 / 5$ \\
\hline & $\begin{array}{l}\text { A good boss recognizes that people are THE essential part of results. A good boss pays attention to the } \\
\text { person as well as the task and inspires and motivates-not command and control. A good boss leaves } \\
\text { her or his personal issues and needs at home. A good boss is a rare and wonderful thing. }\end{array}$ & 5 \\
\hline
\end{tabular}

Figure 2. Examples of responses to the Sentence Completion Test International-Maturity Assessment Profile (SCTi-MAP) and corresponding constructive development theory stage of leadership development.

\section{Measuring Stages of Development}

To determine an individual's stage of leadership, the Sentence Completion Test International-Maturity Assessment Profile (SCTi-MAP) is used. This is Cook-Greuter's revision and expansion of Loevinger's validated and reliable Washington University Sentence Completion Test (23-27). The foundation of the SCTi-MAP is constructive developmental theory (17) and (19). Leadership capacity of professionals is measured by identifying their Action Logic (16) and (19). The SCTi-MAP shifts from viewing people as personality types (eg. MeyersBriggs) to that of identifying their level of meaning making capacity. It focuses on how professionals tend to reason and behave in response to their experience and measures cognitive, affective, and behavioral aspects of being (19).

The SCTi-MAP profile consists of 36 open ended sentence stems such as: "Raising a family ...," "I am ... ", "A good boss ...", "If I had more money ...". Both content (meaning) and sentence structure are significant. The sentence stems, with no right or wrong answers, take 30 to 45 minutes to complete (23). A certified MAP scorer, who has successfully completed an 18-month curriculum, uses a threestep process to score the profile. Initially, each sentence is scored individually with responses compared to a manual of standard responses for each vertical developmental stage or Action Logic. A final score rates the developmental stage demonstrated by the subject (17), (24) and (28). Figure 2 shows examples of sentence completion responses and the corresponding stage.

\section{Leadership Development of ADA Leaders Using Constructive Developmental Theory}

A survey was conducted to explore the leadership development stages of ADA leaders. In 2006, a list of the names of 97 ADA leaders was obtained from the Association's Web site (29). Leaders were recruited electronically to participate in the study using survey methodology (30). These leaders were asked to complete the SCTi-MAP. Questionnaires were completed and electronically sent to the researcher. Completed profiles were individually scored by two certified scorers and reviewed by the originator of the SCTi-MAP. Almost half of the ADA leaders $(n=46)$ participated and completed the testing. Eighty-seven percent of the scores of ADA leaders were in the Conventional tier $(26 \%$ Expert, 61\% Achiever) and 13\% were in the Post-Conventional tier (13\% Individualist).

The strong presence of Stage 4 (Achiever) among ADA leaders is consistent with a profession that is scientifically based. Stage 4 is the latest stage in Conventional adult development before moving to the PostConventional tier. It is rational and deliberate-goal- and outcome-focused. It relies on the objective scientific approach to the world where cause and effect are honored. It is synonymous with Piaget's Era IV stage of physical-cognitive development from age 11 to adult (31). The majority of ADA leaders are at Stage 4, which may indicate comfort in the environment and embedded culture of the dietetics profession. These leaders may move further in development to PostConventional stages if they are aware of their own stage and are given or seek a supportive environment. Developing dietetic leaders from Conventional to Post-Conventional stages could be of great importance to the dietetic profession.

Individuals at the Post-Conventional tier appreciate differences, whereas those in earlier Action Logics look for similarity and stability. Among the ADA leaders who participated in the study, a similar percent $(13 \%)$ scored in the Post-Conventional tier compared to $15 \%$ found in earlier studies among industry and organizational leaders $(20,21)$. These Post-Conventional ADA leaders can provide proficient leadership to the profession and serve as leadership mentors. 


\section{Actions for Developing Leadership Abilities}

- Registered dietitians (RDs) who aspire to be leaders or who are interested in further development their ability to lead can use constructive development theory to learn about the stages of leadership development.

- Using the Action Logics and characteristics of leaders at different stages of development, RDs can self-reflect on their own stage of development.

- Leadership development occurs in sequential stages; therefore, RDs can continue to grow and develop as leaders.

- Identifying and working with leaders who are at later stages of development in work settings organizations, and other social networks may assist in advancing leadership ability.

- RDs can join the American Dietetic Association's new e-mentoring program at www.adaementoring. com to be a mentor or find mentors for leadership development opportunities.

\section{Implications for Leadership Studies and Development}

Actualization of quality leadership remains elusive, disappointing, and unsatisfactory, suggesting that some things affect one's ability to lead (4). A leader's self-awareness of his or her own Action Logic and knowledge of the vertical stages of leadership development may be beneficial for improving leadership ability and evolution over time. The distinction between horizontal and vertical growth is paramount for understanding that leadership knowledge is insufficient to enable a person to develop as a leader. It is through association with others who are at later stages of development and by self reflection of their own Action Logic that one is able to transform (20).

Authentic leaders are defined by Avolio and colleagues as "those who are deeply aware of how they think and behave and are perceived by others as being aware of their own and others' values/morals, perspectives, knowledge and strengths; aware of the context in which they operate and who are confident, hopeful, optimistic, resilient and of high moral character" (32). Truly authentic leaders have been described as knowing "the true north of their moral compass ... and have to understand themselves and the passions that animate their life stories" (33). This self-awareness of authentic leaders is an emerging process consistent with constructive developmental theory that extends beyond the meaning making domains of physicality, emotions, and morality and into how professionals think and not what they know. These factors determine their ability to tolerate complexity and ambiguity and define their professional competence (34-36).

Constructive developmental theory can be used to identify stages of vertical development of leaders within the profession and to better understand factors that contribute to movement from one stage to the next. Leaders should be aware that self transformation and movement to later Action Logic stages is possible. Using self reflection, dietetic leaders can identify their own stage of development and seek opportunities for advancing to later stages, including being open-minded toward persons and situations that they encounter as these can contribute to their development. ADA leaders at these later stages of development can be studied to understand factors contributing to their growth. These factors can inform leadership training for future ADA leaders. To attain exceptional leadership is to distinguish, control, and to direct one's own process of learning and change. Dietetic leaders who reach the Post-Convention stages of development, Stage 4/5 (Individualist), Stage 5 (Strategist), and Stage 5/6 (Alchemist/Magician) may challenge the status quo to new and/or different ways of being and seeing the world and enhancing dietetics practice.

Acknowledgments - This research was partially funded by the University of Nebraska Agricultural Research Division, Lincoln, NE 68583. This research was supported in part through the Hatch Act.

\section{References}

1 A.J. Rourke, The challenge of dietetics. J Am Diet Assoc, 30 (1954), p. 132.

2 D. Rogers, Report on the American Dietetic Association/ADA Foundation Commission on Dietetic Registration 2004: Dietetics professional needs assessment. J Am Diet Assoc, 105 (2005), pp. 1348-1355.

3 M. Smith-Edge, All ADA members are leaders. J Am Diet Assoc, 103 (2003), p. 1452.

4 W.G. Bennis, On Becoming a Leader: The Leadership Classic-Updated and Expanded Perseus Publishing, Philadelphia, PA (2003), pp. 3-4.

5 M.R. Schiller, M.B. Foltz and S.M. Campbell, Dietitians' self perceptions: implications for leadership. J Am Diet Assoc, 93 (1993), pp. 868-874.

6 M.B. Arensberg, M.R. Schiller, V.M. Vivian, W.A. Johnson and S. Strasser, Transformational leadership of clinical nutrition managers. J Am Diet Assoc, 96 (1996), pp. 39-45.

7 J.M. Mislevy, M.R. Schiller, K.N. Wolf and S.C. Finn, Clinical nutrition managers have access to sources of empowerment. J Am Diet Assoc, 100 (2000), pp. 1038-1043.

8 M.H. Burzminski, Demonstrated Leadership Behaviors and Leadership Styles of Entry Level Dietitians [dissertation], St Mary's University, Minneapolis, MN (2002).

9 S.W. Arendt and M.B. Gregoire, Dietetic students perceive themselves as leaders and report that they demonstrate leadership in a variety of contexts. J Am Diet Assoc, 105 (2005), pp. 1289-1294.

10 M.B. Gregoire and S.W. Arendt, Leadership: Reflections over the past 100 years. J Am Diet Assoc., 104 (2004), pp. 395-403.

11 W. Huitt and J. Hummel, Piaget's theory of cognitive development, Educational Psychology Interactive Web site http://www.edpsycinteractive.org/topics/cogsys/piaget.html Accessed May 30, 2011.

12 J. Loevinger, Ego Development JosseyBass, Inc, San Francisco, CA (1976), pp. 13-28.

13 R. Kegan, The Evolving Self: Problem and Process in Human Development Harvard University Press, Cambridge, MA (1982), pp. 86-87.

14 L. Lahey, E. Souvaine, R. Kegan, R. Goodman and S. Felix, A Guide to the Subject-Object Interview: Its Admin- 
istration and Interpretation Harvard University Graduate School of Education Subject-Object Research Group, Cambridge, MA (1988), pp. 1-354.

15 D.E. Beck and C.C. Cowan, Spiral Dynamics: Mastering Values, Leadership and Change Blackwell Publishing, Malden, MA (2006), pp. 48-68.

16 Associates, B. Torbert, Action Inquiry: The Secret of Timely and Transforming Leadership Berret-Koehler Publishers, Inc., San Francisco, CA (2004), pp. 13-23.

17 S. Cook-Greuter, A detailed description of the development of nine action logics in the leadership development framework: adapted from ego development theory, http://www. cook-greuter.com Accessed March 19, 2011.

18 K.M. Eigel and K.W. Kuhnert, Authentic development: leadership development level and executive effectiveness. Monographs in Leadership and Management, 3 (2005), pp. 357-385.

19 S. Cook-Greuter, Making the case for a developmental perspective. Industrial and Commercial Training, 36 (2004), pp. 276-278.

20 D. Rooke and W.R. Torbert, 7 transformations of leadership. Harv Bus Rev, 83 (2005), pp. 67-76.

21 S. Cook-Greuter, Postautonomous Ego Development: A Study of its $\mathrm{Na-}$ ture and Measurement [unpublished dissertation] (updated from 1999), Harvard University, Cambridge, MA (2005).
22 S. Cook-Greuter, Leadership Development Framework and Profile, $\mathrm{Pa}$ per presented at the Development Intensive for Professionals, University of Notre Dame, South Bend, IN (June 2006).

23 S. Cook-Greuter, Map assessment, http://www.cook-greuter.com/SCTiMAPForm.htm Accessed March 19, 2011.

24 J. Loevinger and R. Wessler, Measuring Ego Development 1: Construction and Use of a Sentence Completion Test Jossey-Bass, Inc, San Francisco, CA (1970), pp. 126-133.

25 Stages of ego development, J. Loevinger, Editor, Ego Development: Conceptions and Theories, Jossey-Bass, Inc, San Francisco, CA (1976), pp. 13-28.

$26 \mathrm{~J}$. Loevinger, Construct validity of the sentence completion test for ego development. Applied Psychological Measurement, 3 (1979), pp. 281-311.

$27 \mathrm{~J}$. Loevinger, Reliability and validity of the SCT, J. Loevinger, Editor, Technical Foundations for Measuring Ego Development: The Washington Sentence Completion Test, Lawrence Erlbaum Associates, Mahwah, NJ (1998), pp. 29-39.

28 S. Cook-Greuter, 36-Item SCTi-MAP Manual, (2006), Wayland, MA.

29 American Dietetic Association, Leadership directory, http://www.eatright. org/members/leadershipdirectory. aspx Accessed September 18, 2011.
30 D.A. Dillman, Mail and Internet Surveys: The Tailored Design Method (2nd ed.), Wiley and Sons, New York, NY (2000), pp. 3-218.

31 J. Piaget, Piaget's theory, Handbook of Child Psychology History, Theory, and Methods, Vol 1 ,in: P.H. Mussen, W. Kessen, Editors (4th ed), Wiley and Sons, New York, NY (1983), pp. 103128 (Series ed.) (Vol ed.).

32 B.J. Avolio, W.L. Gardner, F.O. Walumbwa, F. Luthans and D.R. May, Unlocking the mask: a look at the process by which authentic leaders impact follower attitudes and behaviors. The Leadership Quarterly, 15 (2004), pp. 801-823.

33 B. George, Truly Authentic Leadership: Rediscovering the Secrets to Creating Lasting Value, Jossey-Bass, Inc, San Francisco, CA (2003).

34 R. Kegan, In Over Our Heads: The Mental Demands of Modern Life, Harvard University Press, Cambridge, MA (1994), pp. 1-11 307-334.

35 D. Fisher, K. Merron and W.R. Torbert, Human development and managerial effectiveness. Group \& Organizational Studies, 12 (1987), pp. 257-273.

36 K. Merron, D. Fisher and W.R. Torbert, Meaning making and management action. Group \& Organizational Studies, 12 (1987), pp. 274-286. 